\title{
Comparison of Hemodynamic Energy between Expanded Polytetrafluoroethylene and Dacron Artificial Vessels
}

\author{
Jaekwan Lim, Ph.D.', Jong Yun Won, M.D. ${ }^{2}$, Chi Bum Ahn, Ph.D. ${ }^{3}$, Jieon Kim, M.D. ${ }^{2,4}$, Hee Jung Kim, M.D., Ph.D.,4, \\ Jae Seung Jung, M.D., Ph.D. ${ }^{2,4}$
}

'Biomedical Research Center, Korea Testing Laboratory, Jinju; ${ }^{2}$ Department of Thoracic and Cardiovascular Surgery, Korea University College of Medicine; ${ }^{3}$ Biomedical Engineering Research Center, Asan Medical Center; ${ }^{4}$ Korea Artificial Organ Center, Korea University, Seoul, Korea

\section{ARTICLE INFO}

Received October 8, 2020

Revised November 20, 2020

Accepted November 23, 2020

Corresponding author

Jae Seung Jung

Tel 82-2-920-6856

Fax 82-2-928-8793

E-mail heartistcs@korea.ac.kr

ORCID

https://orcid.org/0000-0002-8848-4112
Background: Artificial grafts such as polyethylene terephthalate (Dacron) and expanded polytetrafluoroethylene (ePTFE) are used for various cardiovascular surgical procedures. The compliance properties of prosthetic grafts could affect hemodynamic energy, which can be measured using the energy-equivalent pressure (EEP) and surplus hemodynamic energy (SHE). We investigated changes in the hemodynamic energy of prosthetic grafts.

Methods: In a simulation test, the changes in EEP for these grafts were estimated using COMSOL MULTIPHYSICS. The Young modulus, Poisson ratio, and density were used to analyze the grafts' material properties, and pre- and post-graft EEP values were obtained by computing the product of the pressure and velocity. In an in vivo study, Dacron and ePTFE grafts were anastomosed in an end-to-side fashion on the descending thoracic aorta of swine. The pulsatile pump flow was fixed at $2 \mathrm{~L} / \mathrm{min}$. Real-time flow and pressure were measured at the distal part of each graft, while clamping the other graft and the descending thoracic aorta. EEP and SHE were calculated and compared.

Results: In the simulation test, the mean arterial pressure decreased by $39 \%$ for all simulations. EEP decreased by $42 \%$ for both grafts, and by around $55 \%$ for the native blood vessels after grafting. The in vivo test showed no significant difference between both grafts in terms of EEP and SHE.

Conclusion: The post-graft hemodynamic energy was not different between the Dacron and ePTFE grafts. Artificial grafts are less compliant than native blood vessels; however, they can deliver pulsatile blood flow and hemodynamic energy without any significant energy loss.

Keywords: Hemodynamics, Pulse, Energy, Artificial blood vessles

\section{Introduction}

Prosthetic vessel grafts such as polyethylene terephthalate (Dacron) and expanded polytetrafluoroethylene (ePTFE) have been used for various vascular surgical procedures. Artificial blood vessels have been developed and improved in the last decades, but the patency rates of artificial grafts are $20 \%-30 \%$ at $4-5$ years [1-6]. A mismatch in elastic or compliance properties between the prosthetic grafts and the adjacent native artery has been implicated in the etiology of distal anastomotic myointimal hyperplasia, a major cause of prosthetic graft failure [1]. Reports have also described positive correlations between the compli- ance and patency of artificial grafts [2]. Dacron and ePTFE have lower compliance values $(1.8 \pm 1.2$ and $1.2 \pm 0.3$ per $\mathrm{mm}$ $\mathrm{Hg} \times 10^{-2}$, respectively) than arteries $(8.0 \pm 5.9$ per $\mathrm{mm} \mathrm{Hg} \times$ $10^{-2}$ ) [1]. The difference in the compliance of the artificial grafts can affect hemodynamic energy to the distal part of the bypass graft. To provide help for choosing an artificial graft in bypass surgery, we evaluated hemodynamic energy, which can be measured using the energy-equivalent pressure (EEP) and surplus hemodynamic energy (SHE), for different kinds of artificial grafts. 


\section{Methods}

\section{Computational simulation by COMSOL MULTIPHYSICS}

A simulation study was performed for 2 cases. The geometry, applied function, and EEP solution form are shown in Fig. 1. In the first case, the blood vessel was closed and the graft (Dacron or ePTFE) was open. In the second case,

A

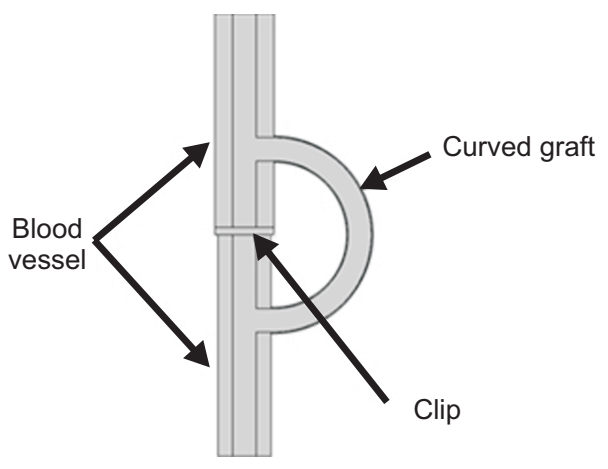

C

E
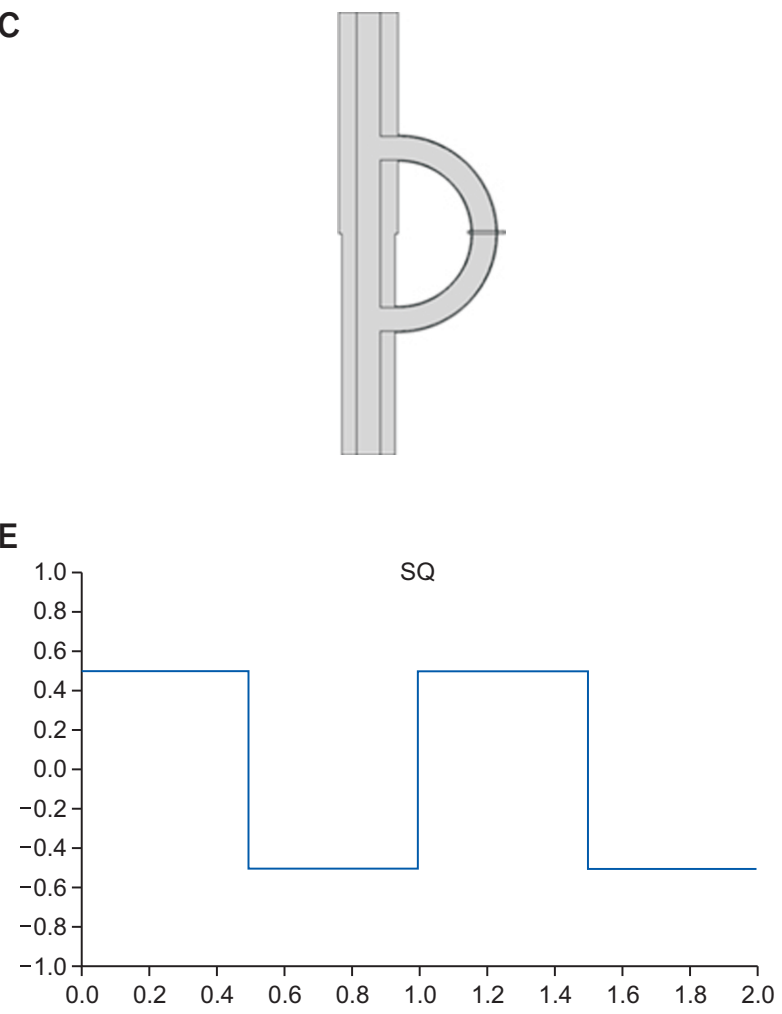

the graft was closed and the blood vessel was open.

The changes in EEP were estimated by a simulation in which each graft (Dacron and ePTFE) replaced the blood vessel, using COMSOL MULTIPHYSICS as a simulation program. In terms of geometry, the blood vessel and the graft were 2-dimensionally modeled in the $x$-y plane with a 300-mm length, 16-mm inner diameter, and 5-mm wall thickness for the blood vessel and 0.5-mm wall thickness, $16-\mathrm{mm}$ inner diameter, and $180^{\circ}$ curvature for the graft.
B

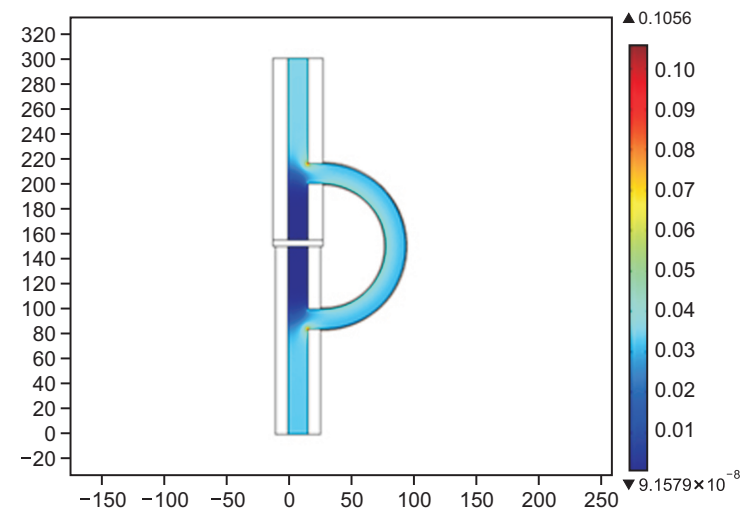

D

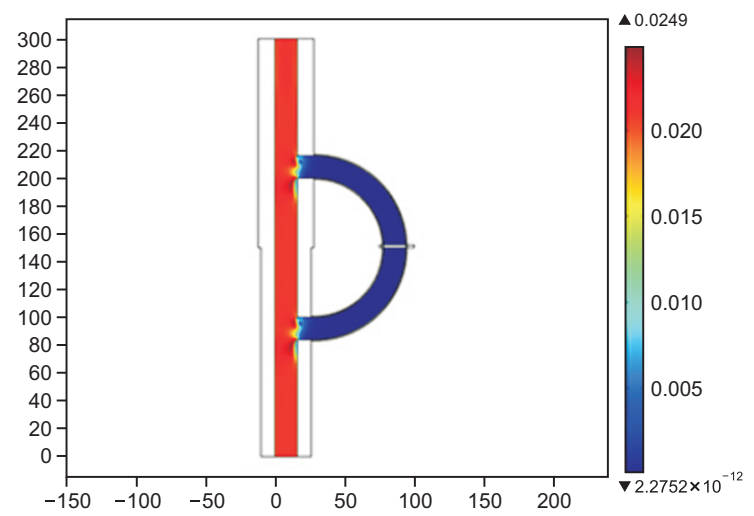

F

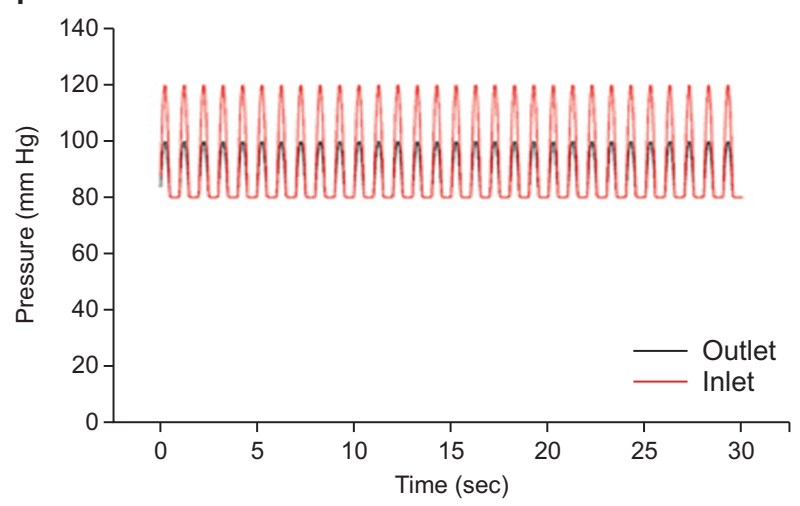

Fig. 1. Geometry for simulation and EEP distribution for graft and blood vessels. The inlet and the outlet were set at $y=0$ and $y=300$. (A, B) The blood vessel is closed by the clip and the graft is open. The blood flows through the graft. (C, D) The graft is closed and the blood vessel is open. The blood flows through the blood vessel. (E) Square function (SQ) and (F) pressure setting for 30 seconds at the inlet and outlet. Inlet pressure (red graph) varies from 80 to $120 \mathrm{~mm} \mathrm{Hg}$ and outlet pressure (black graph) varies from $80 \mathrm{to} 100 \mathrm{~mm} \mathrm{Hg}$. 
As a physics model, a turbulent flow model and solid mechanics were selected. The interaction between the fluid and the wall could be calculated and obtained by setting the boundary load in the solid mechanics component.

In the kappa-epsilon turbulent flow model, fluid properties, inlet, outlet, wall, and initial values were set as properties, and the domain and boundary were then selected for each property. The pressure was given as a modified sinusoidal function, $\mathrm{A} \times \sin (w t) *(S Q(w t)+0.5)+80$, with a frequency of $2 \mathrm{~Hz}$ (A: amplitude, w: angular frequency, SQ $(w t)$ is a square function with an amplitude of 0.5). The amplitude was 40 in the inlet and 20 in the outlet. In the solid mechanics model, the linear elastic material model, the free and initial values, and boundary load were selected as properties, and the domain and boundary were selected for each property. The boundaries contacting the fluid domains were selected as a boundary load to calculate the interaction between the solid mechanics region and turbulent flow region.

Material properties were selected for the blood, vessels, grafts, and iron. Physical parameters such as the Young modulus, Poisson ratio, and density were assigned for solid mechanics as shown in Table 1 . The dynamic viscosity and density, as fluid properties, were set as $5.0 \mathrm{mPa}$ and 1,060 $\mathrm{kg} / \mathrm{m}^{3}$ for blood.

The model was studied in time-dependent mode and the solutions were obtained at every 0.1 seconds from 0 to 30 seconds (Fig. 2). In the solution, the product of the pressure and the flow speed was calculated to obtain EEP. The EEP was measured at the point of $216 \mathrm{~mm}$ for the pre-position and $84 \mathrm{~mm}$ for the post-position. The EEP was estimated by summing the values picked from 9 different $\mathrm{x}$-coordinates for each $\mathrm{y}$-coordinate. The $9 \mathrm{x}$-coordinates were 0,2 , $4,6,8,10,12,14$, and $16 \mathrm{~mm}$.

\section{In vivo study}

We received permission from the Institutional Animal Care and Use Committee for this study (IRB approval no.,

Table 1. Physical parameters of the blood vessels and grafts (ePTFE and Dacron)

\begin{tabular}{lccc}
\hline \multicolumn{1}{c}{ Variable } & Blood vessels & ePTFE & Dacron \\
\hline Young modulus $(\mathrm{GPa})$ & 0.002 & 0.5 & 3.0 \\
Poisson ratio & 0.4 & 0.3 & 0.3 \\
Density $\left(\mathrm{kg} / \mathrm{m}^{3}\right)$ & 1,130 & 2,200 & 1,380 \\
\hline
\end{tabular}

ePTFE, expended polytetrafluoroethylene; Dacron, polyethylene terephthalate.
KUIACUC-2011-206). All experimental animals were cared for and treated according to the Guide for the Care and Use of Laboratory Animals issued by the Korea University School of Medicine, Seoul, South Korea.

Ten Yorkshire swine weighing 30 to $40 \mathrm{~kg}$ were used. An intravenous line was established with a $20 \mathrm{G}$ catheter, and electrocardiographic monitoring was done. After an injection of thiopental sodium $(5-10 \mathrm{mg} / \mathrm{kg})$, tracheostomy was performed and a $6 \mathrm{~F}$ endotracheal tube was inserted for mechanical ventilation. Maintenance of general anesthesia was achieved using 1\%-3\% isoflurane administered via an endotracheal tube with a gas mixture of $\mathrm{N}_{2} \mathrm{O} / \mathrm{O}_{2}(1: 1)$ at a flow rate of $2 \mathrm{~L} / \mathrm{min}$ of each reagent. Mechanical ventilation was maintained with a tidal volume of $10-15 \mathrm{~mL} / \mathrm{kg}$ and a respiratory rate of 30-35 breaths/min and a fraction of inspired oxygen of 0.6 . Vecuronium bromide $(4 \mathrm{mg}$ ) was added for the prevention of spontaneous breathing. After the thoracotomy incision, a Dacron graft of $10 \mathrm{~mm}$ diameter and $100 \mathrm{~mm}$ length was anastomosed in an end-to-side fashion on the descending thoracic aorta. An ePTFE graft of $10 \mathrm{~mm}$ diameter and $100 \mathrm{~mm}$ length was anastomosed by the same method at a site $10 \mathrm{~mm}$ proximal to the anastomosis of the Dacron graft. After anastomosis, a flow meter (TS410 flow meter, ME11PXL probe; Transonic, Ithaca, NY, USA) and arterial pressure line and transducer (PS9030; Sensortechnics, Puchheim, Germany) were placed at the juxtadistal anastomosis site of the descending aorta for measuring mean arterial flow and mean arterial pressure (MAP) (Fig. 3). The pressure and flow waveforms were acquired with a data-acquisition board and MATLAB (Mathworks, Natick, MA, USA) software was used to analyze the waveforms. Extracorporeal circulation was constructed (right atrium to ascending aorta) using a KH-VAD (Korea Hybrid ventricular assist device; Korea Artificial Organ Center, Seoul, Korea), which showed an ability to generate proper hemodynamic energy in our previous study [7]. The extracorporeal circulation was started with ventricular fibrillation and pump flow was fixed at $2 \mathrm{~L} /$ min. The hemodynamic energy of the Dacron graft was measured while blocking the ePTFE graft and descending thoracic aorta with a clamp. The hemodynamic energy of the ePTFE graft was measured while blocking the Dacron graft and descending thoracic aorta with a clamp (Fig. 4).

\section{Hemodynamic energy calculation}

We obtained 30-second waveform data of pressure and flow rate. We measured the data 3 times. The EEP, \%EEP, and SHE were calculated using data from simultaneous 
Blood vessel blocking
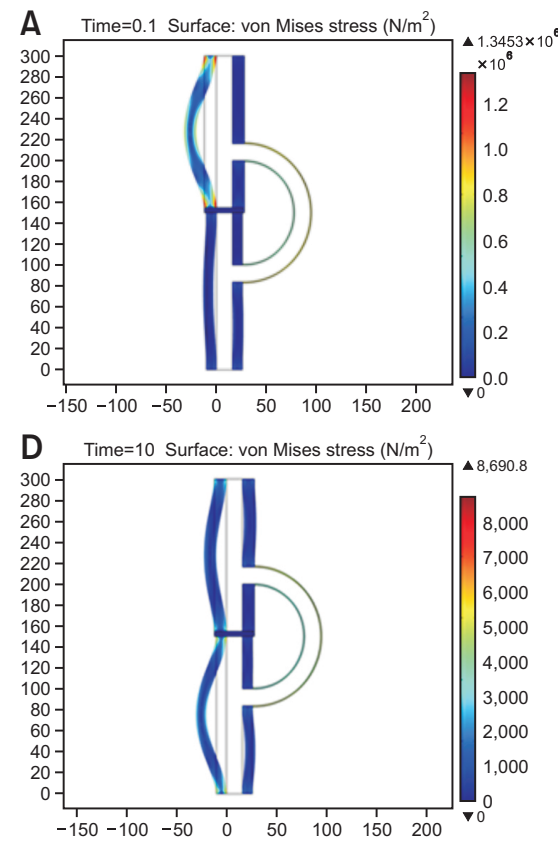

\section{Graft blocking}
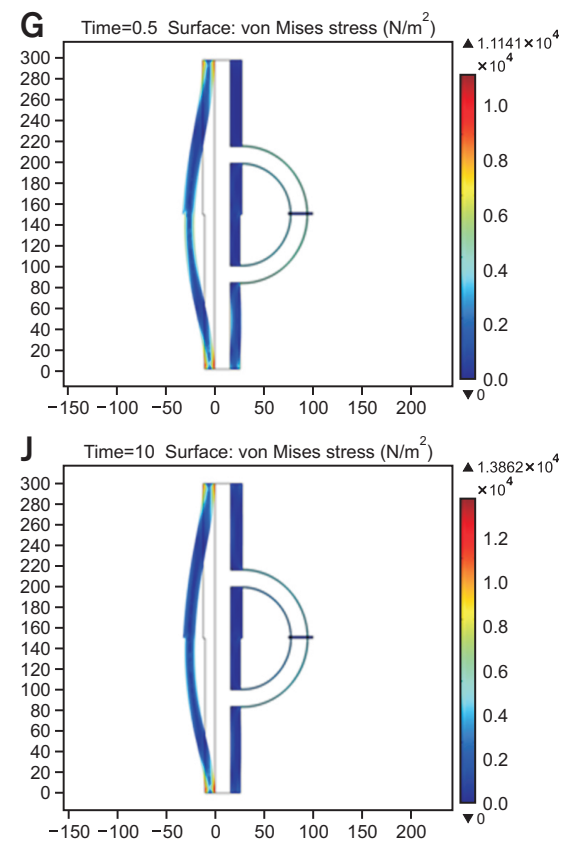
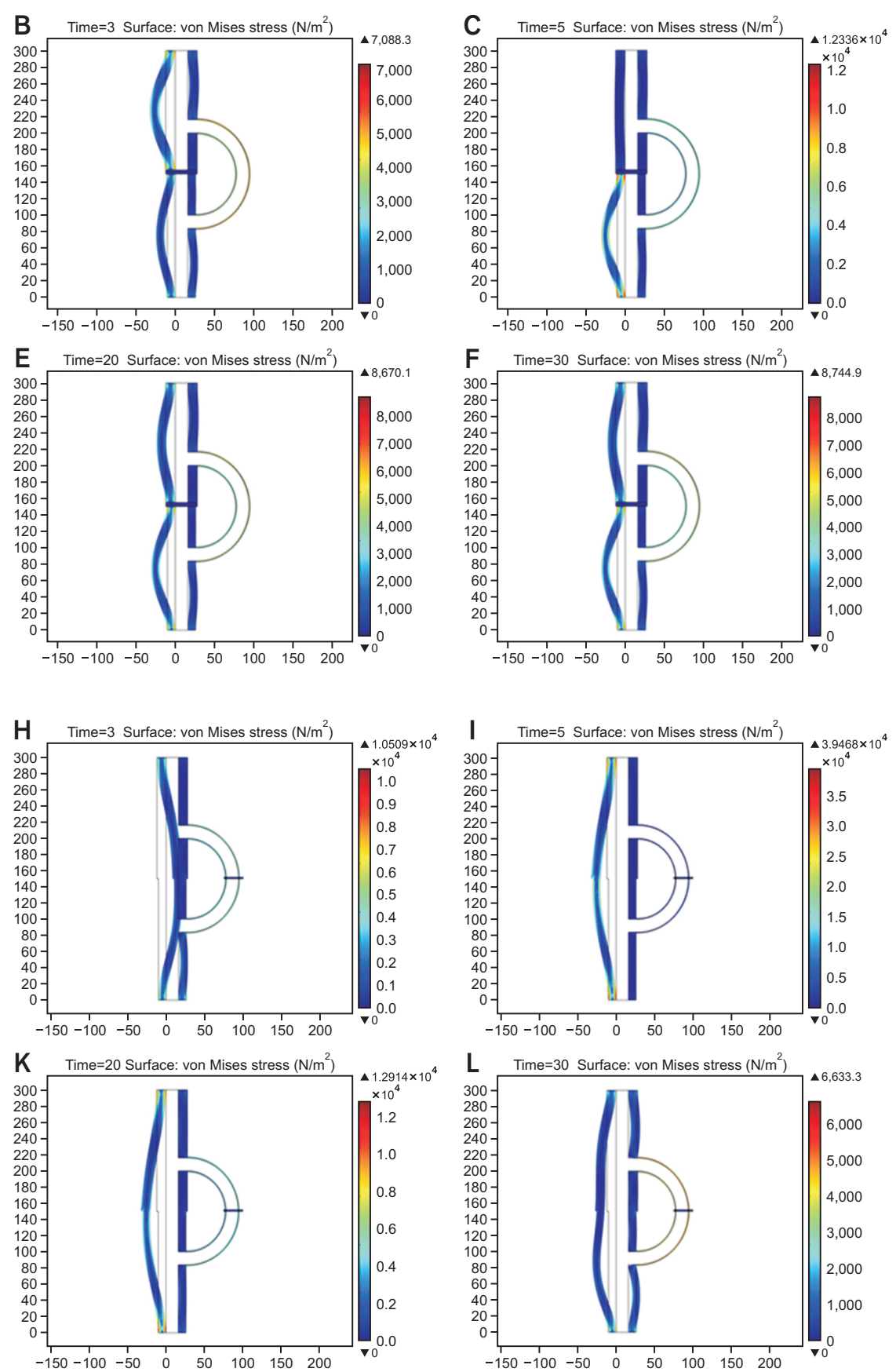

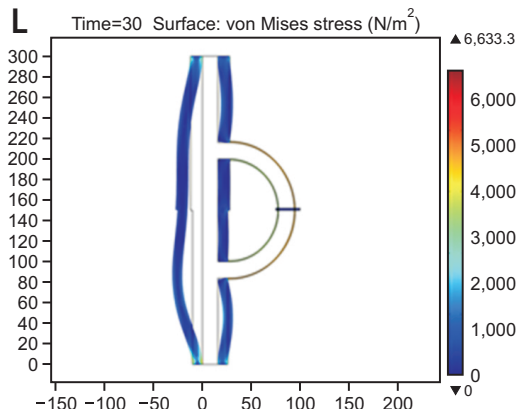

Fig. 2. Deformation of the blood vessel by stress from blood pressure as time passes. Deformations of the blood vessel at $0.5,3,5,10$, 20 , and 30 seconds are displayed for when $(A-F)$ the blood vessel is closed and $(G-L)$ the graft is closed.

flow (f), pressure (p), and MAP readings for an interval of time $\left(\mathrm{t}_{1}-\mathrm{t}_{2}\right)$ as follows [8]:

$$
\begin{aligned}
& \operatorname{EEP}(m m H G)=\left(\int \mathrm{pfdt}\right) /\left(\int \mathrm{fdt}\right) \\
& \% \operatorname{EEP}(\%)=(\mathrm{EEP}-\mathrm{MAP}) / \mathrm{MAP} \times 100 \\
& \mathrm{SHE}\left(\mathrm{ergs} / \mathrm{cm}^{3}\right)=1,332 \times(\mathrm{EEP}-\mathrm{MAP})
\end{aligned}
$$

The Mann-Whitney U-test in Statistica ver. 6.0 (StatSoft Inc., Tulsa, OK, USA) was used to determine intergroup significances using a $\mathrm{p}$-value of $<0.05$. All results are expressed as mean \pm the standard deviation of the mean value. 


\section{Results}

In the simulation test, when pressure was applied, the blood vessel expanded and fluctuated according to the pressure, but the graft hardly changed during the whole process (Fig. 2). When the blood vessel was blocked, the upper part of the blood vessel expanded and then at $5 \mathrm{sec}$ onds, the lower part of the blood vessel started to expand. When the graft was blocked case, most of the fluctuation happened on the left-side wall from the beginning to end.

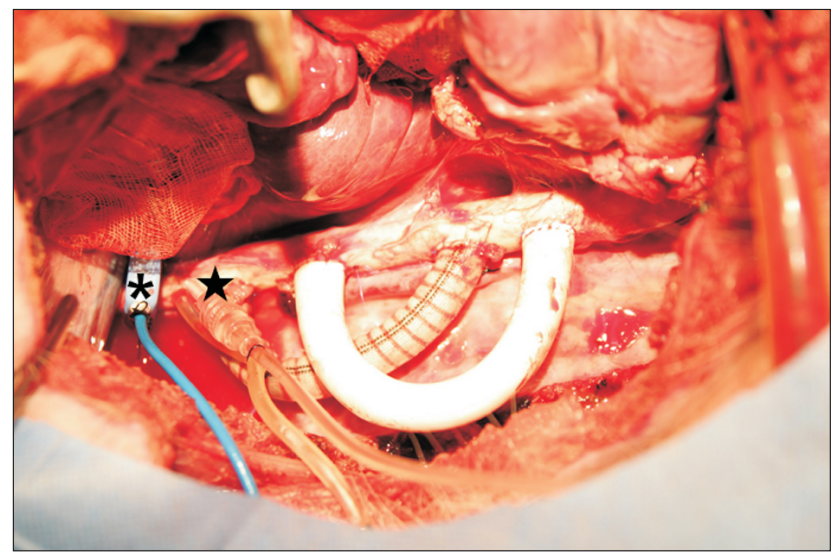

Fig. 3. Flow meter probe and arterial pressure line were placed on the descending aorta at the juxta-distal anastomosis site to measure mean arterial flow and mean arterial pressure. $*$ indicates flow meter and $\star$ indicates pressure line.
This occurred because the Young modulus of the blood vessels was much smaller than those of the grafts. The fixed constraints were set not to be affected by pressure. The MAP decreased from $102 \mathrm{~mm} \mathrm{Hg}$ at the inlet to 95 $\mathrm{mm} \mathrm{Hg}$ at the outlet and the decay ratio was about $6 \%$ for all grafts. The EEP for the Dacron and ePTFE grafts was $15.96 \mathrm{~mm} \mathrm{Hg}$ at the pre-position $(\mathrm{y}=40)$ and $11.77 \mathrm{~mm} \mathrm{Hg}$ at the post-position $(y=260)$, and the decay ratio was about $26 \%$.

When the EEP was measured for blood vessels without a graft, the EEP was conserved, with a value of $28.7 \mathrm{~mm} \mathrm{Hg}$. This was $76 \%$ larger than the EEP when the blood vessel was closed, and this difference was mainly caused by the geometrical structure of the bloodstream (Table 2).

In in vivo test, there was no significant difference between Dacron and ePTFE grafts in terms of EEP and SHE (EEP: $64.87 \pm 11.31 \mathrm{~mm} \mathrm{Hg}$ for Dacron versus $56.83 \pm 13.41$ $\mathrm{mm} \mathrm{Hg}$ for ePTFE, SHE: 7,116.75 $\pm 3,031.73 \mathrm{ergs} / \mathrm{cm}^{3}$ for Dacron versus $7,176.46 \pm 3,100.76 \mathrm{ergs} / \mathrm{cm}^{3}$ for ePTFE). The percent changes of EEP were not significantly different (\%EEP: $8.92 \% \pm 3.01 \%$ for Dacron versus $9.54 \% \pm 3.52 \%$ for ePTFE) (Table 3).

\section{Discussion}

Vascular disease has become more common as a result of changes in dietary and lifestyle habits. Since the rapid development of percutaneous transluminal angioplasty (PTA)
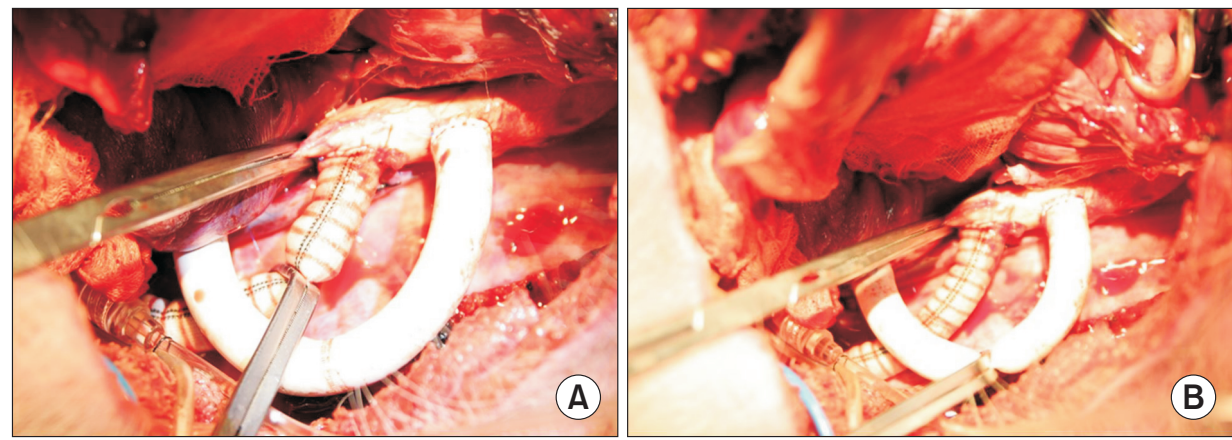

Fig. 4. (A) The hemodynamic energy of the ePTFE graft was measured with the Dacron graft and descending thoracic aorta blocked with a clamp. (B) The hemodynamic energy of the Dacron graft was measured with the ePTFE graft and descending thoracic aorta blocked with a clamp. ePTFE, expended polytetrafluoroethylene; Dacron, polyethylene terephthalate.

Table 2. MAP and EEP by simulation for 2 grafts and a blood vessel

\begin{tabular}{lcccccc}
\hline \multirow{2}{*}{ Graft } & \multicolumn{2}{c}{ MAP $(\mathrm{mm} \mathrm{Hg})$} & & \multicolumn{3}{c}{ EEP $(\mathrm{mm} \mathrm{Hg})$} \\
\cline { 2 - 3 } \cline { 5 - 7 } & Pre & Post & Pre & & Post & Decay ratio (\%) \\
\hline ePTFE & 102.2 & 93.7 & & 16.0 & 11.8 & 26.3 \\
Dacron & 102.3 & 93.7 & & 15.9 & 11.7 & 26.4 \\
Blood vessels & 102.2 & 94.5 & & 28.7 & 28.3 & 1.4 \\
\hline
\end{tabular}

Values are presented as means.

MAP, mean arterial pressure; EEP, energy-equivalent pressure; ePTFE, expended polytetrafluoroethylene; Dacron, polyethylene terephthalate. 
Table 3. Comparison of the hemodynamic energy between Dacron and ePTFE at the juxta-distal anastomosis site

\begin{tabular}{lccccc}
\hline \multicolumn{1}{c}{ Group } & MAP $(\mathrm{mm} \mathrm{Hg})$ & Mean flow $(\mathrm{L} / \mathrm{min})$ & EEP $(\mathrm{mm} \mathrm{Hg})$ & \%EEP $(\%)$ & $\mathrm{SHE}\left(\mathrm{ergs} / \mathrm{cm}^{3}\right)$ \\
\hline Dacron & $59.53 \pm 10.00$ & $1.25 \pm 0.35$ & $64.87 \pm 11.31$ & $8.92 \pm 3.01$ & $7,116.75 \pm 3,031.73$ \\
ePTFE & $56.83 \pm 13.41$ & $1.32 \pm 0.29$ & $62.21 \pm 14.53$ & $9.54 \pm 3.52$ & $7,176.46 \pm 3,100.76$ \\
p-value & $\mathrm{NS}$ & $\mathrm{NS}$ & $\mathrm{NS}$ & $\mathrm{NS}$ & $\mathrm{NS}$ \\
\hline
\end{tabular}

Values are presented as mean \pm standard deviation.

Dacron, polyethylene terephthalate; ePTFE, expended polytetrafluoroethylene; MAP, mean arterial pressure; EEP, energy-equivalent pressure; SHE, surplus hemodynamic energy; NS, not significant.

using medical imaging equipment, PTA has been tried in cases where vascular disease could not be controlled or improved by medical therapy [9-12]. However, if the patient's vascular status is severe and PTA is inappropriate, bypass surgery becomes inevitable. Autologous blood vessels (greater saphenous vein or deep femoral vein) have been used for bypass surgery for peripheral arteries because their patency is better than that of artificial grafts $[3,4]$. However, artificial grafts are still used in many bypass surgical procedures. Particularly, in patients with varicose veins, venous thrombosis, or no appropriate veins after the use of the saphenous vein in previous coronary artery bypass surgery, the use of an artificial graft is necessary [4]. Furthermore, during the bypass surgery for a large vessel like the aorta, the use of autologous blood vessels has limitations due to the size discrepancy.

When choosing a prosthetic graft, the patency rate is an important issue. Walden et al. [2] reported a positive correlation between the graft compliance and patency when grafts were used in infra-inguinal bypass surgery. The patency rate of Dacron was higher (65\% versus $60 \%)$ than that of ePTFE at 1 year after graft surgery and both types of grafts had a $42 \%$ patency rate at 2 years post-graft surgery [2]. Although higher compliance in artificial vessels has been associated with a higher rate of patency, it has not been reported which artificial graft is superior from the viewpoint of hemodynamic energy.

Many articles have shown that pulsatile flow has superior benefits for tissue perfusion than non-pulsatile flow [1319]. Ündar et al. [20] quantified pulsatile flow using EEP and SHE. They used those parameters to explain that excessive energy that was created by pulsatile flow. Pulsatile flow with higher EEP indicates the presence of extra energy to perfuse organs or tissue. In our results, the \%EEP was around $8 \%-9 \%$ at the post-graft sites of both Dacron or ePTFE without a significant difference between the 2 types of artificial vessels. Our previous in vivo study showed that a normal pulsatile flow state had a \%EEP of $8 \%-10 \%$ [21]. The pulsatile hemodynamic energy did not change after passing through the grafts. In addition, EEP was found to be preserved in prosthetic grafts compared to blood vessels in our simulation. Pressure and EEP in the cardiopulmonary bypass (CPB) circuit was significantly higher than in blood vessels, and this could be easily observed in every CPB state.

Due to the acute nature of this study, problems related to endothelial hyperplasia and subsequent graft failure could not be investigated, as these are all future events. Therefore, all expectations of future graft behavior would be speculative, especially regarding the implications of the EEP and SHE in the artificial grafts that were studied. Furthermore, the durability of the artificial grafts used as peripheral grafts applies in a limited capacity in reference to this paper, which is another limitation of this study. Therefore, long-term studies related to hemodynamic energy in artificial grafts, especially those with a small diameter, are planned.

In conclusion, Dacron and ePTFE are less compliant than native blood vessels; however, they can deliver pulsatile blood flow and hemodynamic energy without any significant energy loss. There was no difference in hemodynamic energy between Dacron and ePTFE.

\section{Conflict of interest}

No potential conflict of interest relevant to this article was reported.

\section{ORCID}

Jaekwan Lim: https://orcid.org/0000-0002-5637-6141 Jong Yun Won: https://orcid.org/0000-0002-9944-7261 Chi Bum Ahn: https://orcid.org/0000-0001-7790-513X Jieon Kim: https://orcid.org/0000-0002-1938-6412 Hee Jung Kim: https://orcid.org/0000-0001-5254-1405 Jae Seung Jung: https://orcid.org/0000-0002-8848-4112 


\section{References}

1. Tai NR, Salacinski HJ, Edwards A, Hamilton G, Seifalian AM. Compliance properties of conduits used in vascular reconstruction. $\mathrm{Br} \mathrm{J}$ Surg 2000;87:1516-24.

2. Walden R, L'Italien GJ, Megerman J, Abbott WM. Matched elastic properties and successful arterial grafting. Arch Surg 1980;115:11669 .

3. Chlupac J, Filova E, Bacakova L. Blood vessel replacement: 50 years of development and tissue engineering paradigms in vascular surgery. Physiol Res 2009;58 Suppl 2:S119-39.

4. Konig G, McAllister TN, Dusserre N, et al. Mechanical properties of completely autologous human tissue engineered blood vessels compared to human saphenous vein and mammary artery. Biomaterials 2009;30:1542-50

5. Soldani G, Losi P, Bernabei M, et al. Long term performance of smalldiameter vascular grafts made of a poly(ether)urethane-polydimethylsiloxane semi-interpenetrating polymeric network. Biomaterials 2010;31:2592-605.

6. Xie X, Guidoin R, Nutley M, Zhang Z. Fluoropassivation and gelatin sealing of polyester arterial prostheses to skip preclotting and constrain the chronic inflammatory response. J Biomed Mater Res B Appl Biomater 2010;93:497-509.

7. Jeong GS, Hwang CM, Nam KW, et al. Development of a closed air loop electropneumatic actuator for driving a pneumatic blood pump. Artif Organs 2009;33:657-62.

8. Shepard RB, Simpson DC, Sharp JF. Energy equivalent pressure. Arch Surg 1966;93:730-40.

9. Canaud L, Ozdemir BA, Belli AM, Loftus IM, Thompson MM, Hinchliffe RJ. Infrainguinal angioplasty with drug-eluting stents and balloons. J Vasc Surg 2014;59:1721-36.

10. Wright G. Hemodynamic analysis could resolve the pulsatile blood flow controversy. Ann Thorac Surg 1994;58:1199-204.

11. Wu R, Yao C, Wang S, et al. Percutaneous transluminal angioplasty versus primary stenting in infrapopliteal arterial disease: a meta-anal- ysis of randomized trials. J Vasc Surg 2014;59:1711-20.

12. Yuan L, Bao J, Zhao Z, Lu Q, Feng X, Jing Z. Clinical results of percutaneous transluminal angioplasty for thromboangiitis obliterans in arteries above the knee. Atherosclerosis 2014;235:110-5.

13. Kim HK, Son HS, Fang YH, Park SY, Hwang CM, Sun K. The effects of pulsatile flow upon renal tissue perfusion during cardiopulmonary bypass: a comparative study of pulsatile and nonpulsatile flow. ASAIO J 2005;51:30-6.

14. Lim CH, Son HS, Baek KJ, et al. Comparison of coronary artery blood flow and hemodynamic energy in a pulsatile pump versus a combined nonpulsatile pump and an intra-aortic balloon pump. ASAIO J 2006;52:595-7.

15. Travis AR, Giridharan GA, Pantalos GM, et al. Vascular pulsatility in patients with a pulsatile- or continuous-flow ventricular assist device. J Thorac Cardiovasc Surg 2007;133:517-24.

16. Son HS, Sun K, Fang YH, et al. The effects of pulsatile versus non-pulsatile extracorporeal circulation on the pattern of coronary artery blood flow during cardiac arrest. Int J Artif Organs 2005;28: 609-16.

17. Jung JS, Son HS, Lim CH, Sun K. Pulsatile versus nonpulsatile flow to maintain the equivalent coronary blood flow in the fibrillating heart. ASAIO J 2007;53:785-90.

18. Sezai A, Shiono M, Orime Y, et al. Major organ function under mechanical support: comparative studies of pulsatile and nonpulsatile circulation. Artif Organs 1999;23:280-5.

19. Ji B, Undar A. Comparison of perfusion modes on microcirculation during acute and chronic cardiac support: is there a difference? Perfusion 2007;22:115-9.

20. Undar A, Masai T, Beyer EA, Goddard-Finegold J, McGarry MC, Fraser CD Jr. Pediatric physiologic pulsatile pump enhances cerebral and renal blood flow during and after cardiopulmonary bypass. Artif Organs 2002;26:919-23.

21. Lim CH, Son HS, Fang YH, Lee JJ, Lee HW, Sun K. The effects of dopamine, ephinephrine, and esmolol on the hemodynamic energy in terms of the energy equivalent pressure. ASAIO J 2007;53:791-4. 